\title{
Spatial Pattern Distribution of Wind and Solar Energy in USA
}

\author{
Ariel Johnson', Hongmei Wang ${ }^{2, *}$ \\ ${ }^{1}$ Department of Biological Sciences, Northern Kentucky University, United States of America \\ ${ }^{2}$ Department of Computer Science, Faculty of GIS, Northern Kentucky University, United States of America
}

Copyright $\odot 2019$ by authors, all rights reserved. Authors agree that this article remains permanently open access under the terms of the Creative Commons Attribution License 4.0 International License

\begin{abstract}
Renewable energy, compared to non-renewable energy, is cleaner for the environment. Previous studies on the United States of America (USA) renewable energy mainly focused on assessment of renewable emerging resource potential in some areas in USA. Spatial distribution patterns of renewable energy are valuable to have better management of renewable energy exploration. The objective of this study is to complete spatial pattern analyses of the USA renewable energy with focus on wind and solar energy. Several GIS tools, including High/Low Clustering, Grouping Analysis and Hotspot Analysis, are applied to analyze the energy spatial patterns. The analysis results show that solar energy is clustered at the southwest USA while wind is highly variable and dependent on the local geographic environment. The study results will be helpful to possible growth in this industry.
\end{abstract}

Keywords Wind Energy, Solar Energy, Spatial Pattern Analyses, USA

\section{Introduction}

This research is about energy in USA from an environmental scientist lens. Energy in USA is crucial to people's daily activities. The majority of the energy consumed in USA is non-renewable. The energy that was consumed in USA in 2010 came from $44.7 \%$ coal and $23.9 \%$ natural gas (Squalli, 2017). As environmental scientists, the goal for us is to change the resource that the majority of the energy comes from. Renewable energy is available to use, instead of using non-renewable resources. Renewable energy is cleaner than non-renewable energy. If $80 \%$ of the energy consumed in USA was generated through renewable resources, the greenhouse gas emissions could be decreased by $82 \%$ (Squalli, 2017).

Geographic Information Systems (GIS) are computer information systems for capturing, storing, querying, analyzing, and displaying geographically referenced data (Chang, 2015). GIS has been applied in the field of renewable energy world-wide. For example, in Afghanistan wind and solar power was examined for their energy potential (Anwarzai \& Nagasaka, 2017), in India wind power was determined to be useful in remote areas (Jangid et al., 2016) and in Egypt off-shore winds were examined using GIS (Mahdy \& Bahaj, 2018).

This study focuses on renewable energy in USA. Similarly, GIS has also been widely applied for renewable energy in the USA (Defne, 2010; Fish \& Calvert, 2016; Hemery, Henkel, \& Cochrane, 2017; Niblick \& Landis, 2016; Schelly \& Price, 2014), specifically in this case in terms of site suitability (Brewer, Ames, Solan, Lee, \& Carlisle, 2015), and in this study for renewable energy storage (Zhang, Cho, Luck, \& Mago, 2018). Most of these existing studies focus on analyzing the renewable energy potential assessment, such as usable energy and efficiency (Groppi, de Santoli, Cumo, \& Astiaso Garcia, 2018), urban solar roof potentials (Elmore, 2017), and geothermal energy potentials (Augustine, 2012). The National Renewable Energy Laboratory has completed a USA renewable energy analysis on the state level energy potentials (Lopez, Roberts, Heimiller, Blair, \& Porro, 2012). In their study, solar energy is in four categories, including rural, urban, concentrating and rooftop. Wind is examined through on shore and off shore power. Through looking at these different variables, they found that some states would be better suited to certain types of solar or wind energy.

Little research has been conducted to examine the spatial distribution patterns of those renewable resources, which allows for a more in depth understanding of the renewable resource distribution. In depth understanding is needed because only $11 \%$ of the energy consumption in the US is residential (Mohtasham, 2015). When a majority of the energy consumption is from businesses or commercial needs, there needs to be a large amount of renewable energy resource distribution data to work with in order to make investments on developing renewable energy to 
support the needs.

The goal of this study is to examine spatial distribution patterns of the USA renewable energy, in particular, the solar and wind energy, with using spatial pattern analysis methods. Spatial patterns of non-renewable energy like coal have not been examined due to the amount of data available about the reserves (Milici, Flores, \& Stricker, 2013; Mohtasham, 2015; Xu, Song, Wu, \& Zeng, 2015). With GIS data available to renewable energy in USA, we are going to analyze the renewable energy data with use of appropriate GIS spatial pattern analysis methods. In this study, three spatial analysis methods, including clustering analysis, grouping analysis, and hotspots analysis are applied. Wind energy and solar energy are focused to illustrate the potential of our methods. Solar power is captured through photovoltaic cells (Hasan, Sarwar, \& Shah, 2018). Wind power is harnessed through wind turbines spinning an alternator (Hau, 2006).

The spatial distribution patterns of renewable energy are valuable to the states and companies who are investing in renewable energy. While the individual state energy potentials from the previous studies are important, with wind especially there is a high degree of variability that calls for a more in depth look into their spatial distribution patterns.

\section{Methodology}

We first explored the digital data warehouse on the internet and collected relevant data, then, preprocessed the data so that they are ready to be analyzed in GIS tools. Finally, we used several GIS tools and analyzed the data and interpreted the resulting maps. The methodology stages are shown in Figure 1.

\subsection{Data Source}

The solar and wind datasets were downloaded from the USA government GIS data warehouse on "www.data.gov". Both of them were generated by the National Renewable Energy Laboratory (https://www.nrel.gov/index.html). The wind dataset is classified by power classes which is a range of wind power. There are six power classes represented in the dataset. The solar energy dataset (annual energy density data) is represented by kilowatt-hours per meter squared. These datasets are appropriate for this study because they show in depth the spatial variations of wind and solar power.

\subsection{Data Preprocessing}

The solar GIS data was originally transferred from raster data as very small square polygons, which was hard for GIS to display them and also hard for the software to process them due to the super large number of polygons in the data.

In order to display and process the solar data, we had to round the original data to a degree of one hundred so it could be viewed more easily as a choropleth map. Rounding is performed by adding a new field to the attribute table of the solar GIS data, then using the field calculator to calculate the new field value from the original annual solar energy field value. The new field value is calculated by dividing the original annual field by 100 first and then multiplying by 100 . The new field rounds the annual data to the 100th decimal. After the rounding of the annual field was completed, the GIS tool, Dissolve, was used to create polygons of equal values. This tool dissolves the boundaries of original small square polygons of equal value. The processed data have way much less polygons than the original solar data. The preprocessed annual solar energy density data is shown in Figure 2.

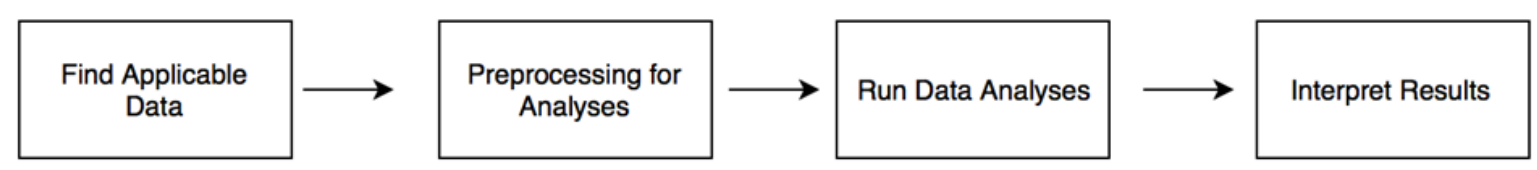

Figure 1. Stages of Research and Analysis 


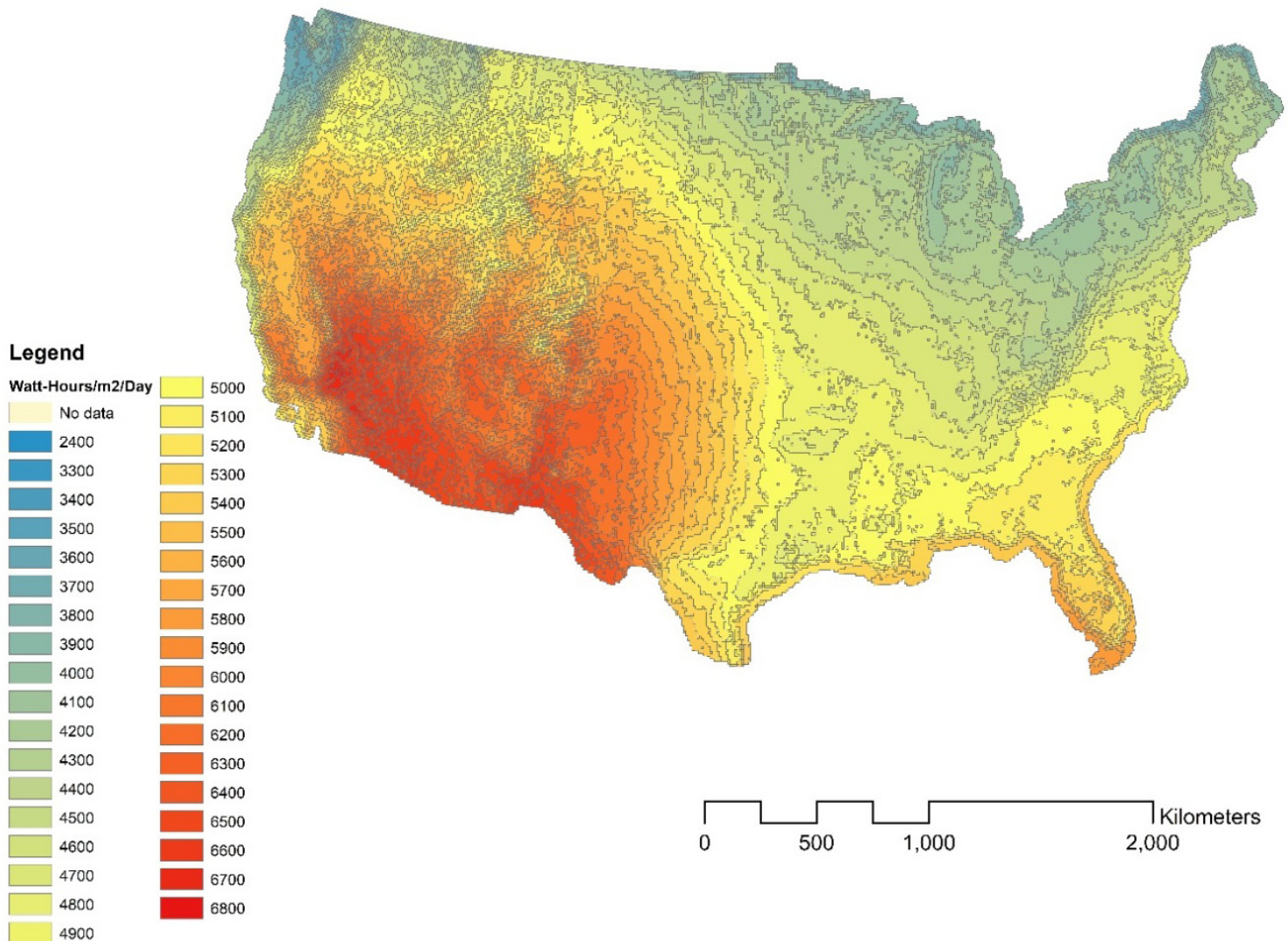

Figure 2. Annual Solar Energy Density on the Territory of USA

Wind data did not require preprocessing. The attribute, power class, was displayed on a choropleth map shown below as Figure 3.

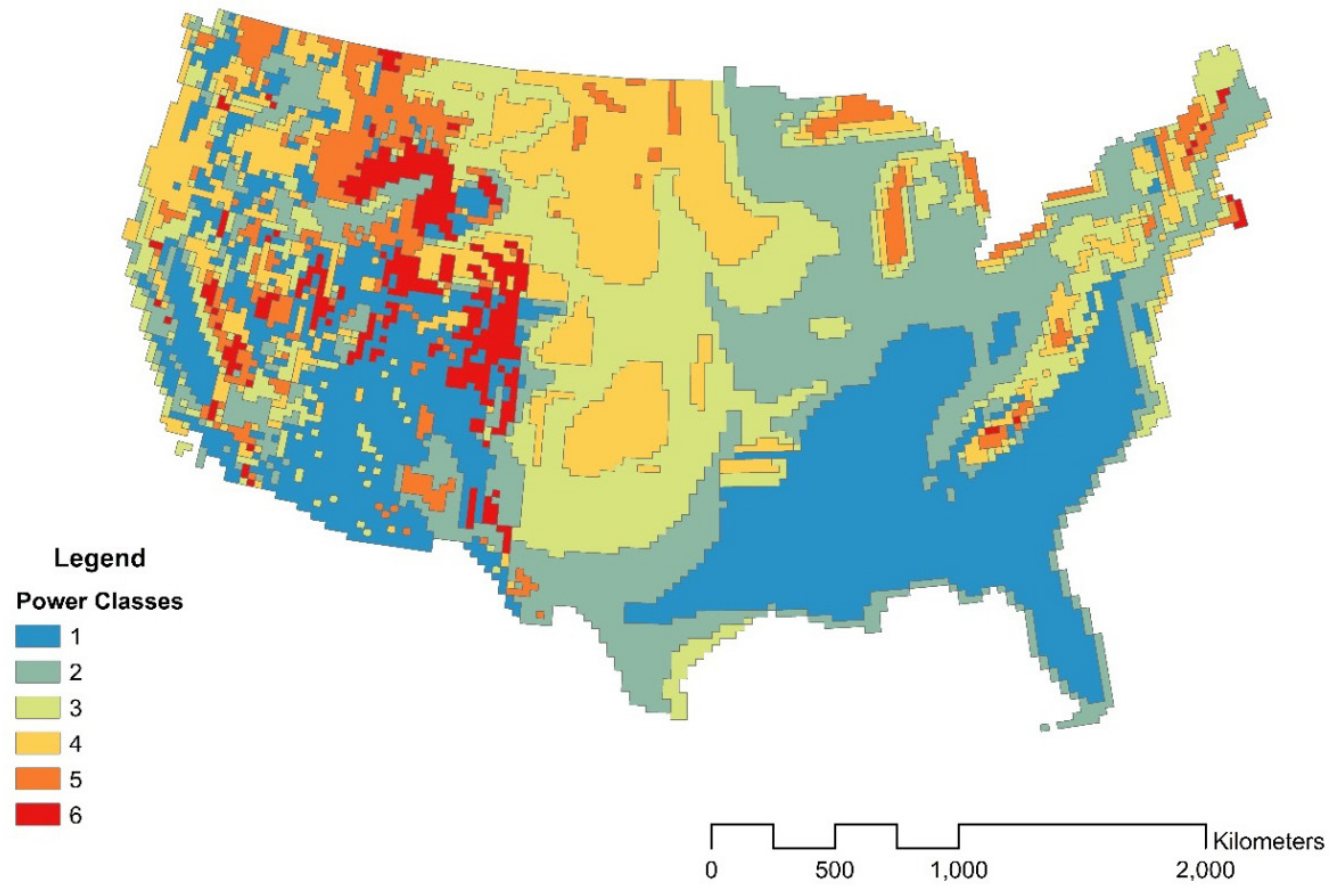

Figure 3. Wind Power Classes on the Territory of USA 


\subsection{Data Analysis}

The three spatial analysis methods that we used are High/Low Clustering, Grouping Analysis and Hot Spot Analysis. High/Low Clustering allows an understanding of if globally, the spatial pattern is significantly different from random distribution. Grouping Analysis shows the re-grouped data under the condition where given an arbitrary number to group the data, the inner group differences are minimized and the outer group differences are maximized. Hot spot analysis shows local concentrations of high or low values from a given attribute in the GIS data.

At first, we applied High/Low Clustering to test whether the solar and wind energy distribution is random or not. The solar energy clustering analysis was based on the original non-rounded annual data and the wind analysis was based on the power class data. The conceptualization of spatial relationships between spatial features (represented by energy polygons in the GIS data) is set by the inverse distance method (based on the Euclidian distance). This means that in this analysis, nearby neighboring energy features are considered to have a larger influence on the computations for a target energy feature than energy features that are far away. An analysis report was generated from the high/low clustering analysis for each energy data.

Second, we conducted the Grouping Analysis on both energy datasets. We analyzed the rounded annual energy density field (due to data constraints in the Grouping Analysis) for the solar energy and the power class for the wind energy. For both of them, we selected 5 groups as the target group number. For solar, we set up the analysis with a spatial constraint of Delaunay triangulation to only allow groups with shared boundaries considering that the solar energy usually depends on the location on the Earth (related to the Sun location). For the wind, we did not set up the spatial constraints because wind has a more sporadic pattern related to the local terrain. A result map was generated for each energy analysis.

Third, we applied the Hot Spot analysis tool on both datasets. Similar to the Grouping Analysis above, we used the rounded annual energy density field for the solar energy and the power class for the wind energy. The conceptualization of spatial relationships between spatial features (energy polygons in the GIS data) was set to the fixed distance band (based on the Euclidian distance). This means that in this analysis, each feature is analyzed within the context of its neighboring features. The neighborhood of each feature is defined with the distance band/threshold distance value. A result map was generated for each energy analysis.

\section{Findings}

This section describes the analysis results from application of three spatial pattern analysis methods above for each energy resource.

\subsection{High/Low Clustering Analysis Results}

The high/low clustering report for solar (Figure 4) has a $z$-score of 59.34, which means that there is less than a $1 \%$ likelihood that the highly clustered pattern could be random, and that is, the spatial distribution of the USA annual solar energy density tends to be clustered. This analysis result is as expected. The solar energy density distribution is not random due to the Earth's geometry relate to the Sun's location. 
High-Low Clustering Report

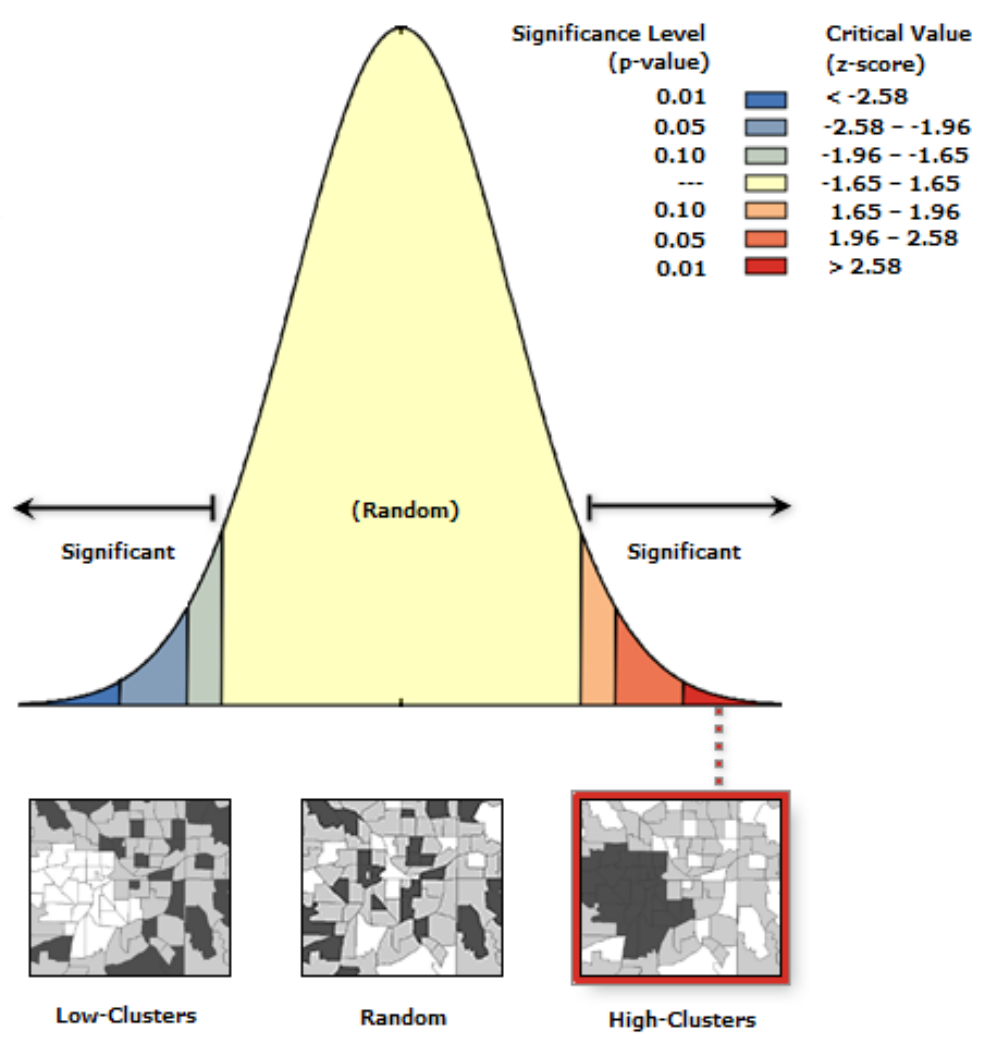

Given the z-score of 59.3367870342 , there is a less than $1 \%$ likelihood that this high-clustered pattern could be the result of random chance.

General G Summary

\begin{tabular}{|c|c|}
\hline Observed General G: & 0.000000 \\
\hline Expected General G: & 0.000000 \\
\hline Variance: & 0.000000 \\
\hline z-score: & 59.336787 \\
\hline p-value: & 0.000000 \\
\hline
\end{tabular}

Figure 4. High-Low Clustering Analysis Report of USA Annual Solar Energy Density

The high/low clustering report for wind (Figure 5) yields a z-score of 0.94, which means that the pattern does not appear to be significantly different than random. Due to the highly variable patterns of wind, it is considered to be a random pattern in terms of clustering. 
High-Low Clustering Report

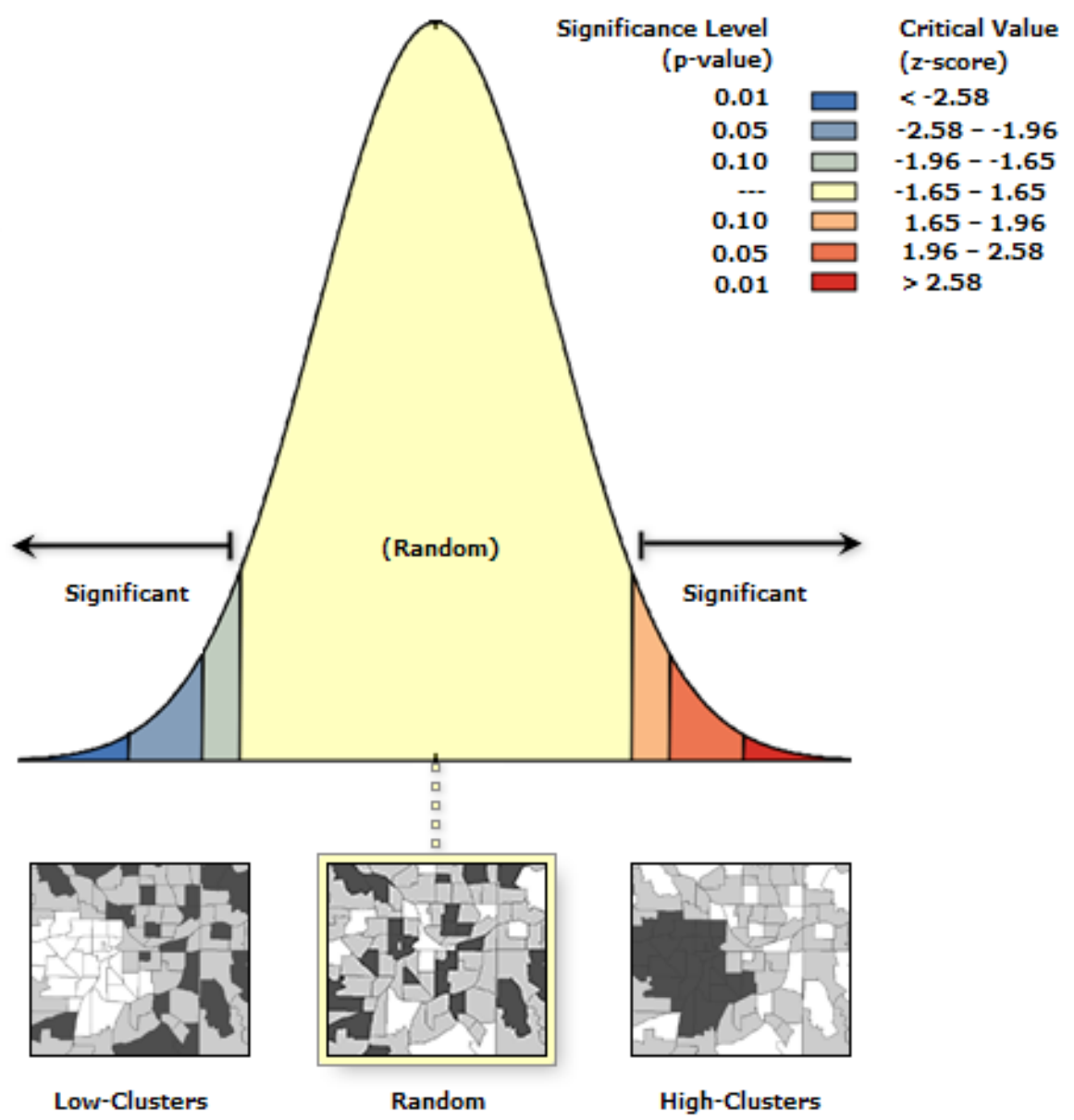

Given the z-score of 0.943124212863 , the pattern does not appear to be significantly different than random.

General G Summary

\begin{tabular}{|c|l|}
\hline Observed General G: & 0.000000 \\
\hline Expected General G: & 0.000000 \\
\hline Variance: & 0.000000 \\
\hline z-score: & 0.943124 \\
\hline p-value: & 0.345617 \\
\hline
\end{tabular}

Figure 5. High-Low Clustering Analysis Report of USA Wind Energy Power Classes

\subsection{Grouping Analysis Results}

The grouping analysis result is compared to the original map to analyze the energy value in the analysis. Comparing the wind grouping analysis result map (Figure 6) to the original map (Figure 3), there are a lot of similarities. The same areas that are grouped together are either the same class or just one class away. The wind grouping analysis result shows that there is a high level of variability on the wind energy in most areas in USA (except for the southern USA). This result is consistent with the result from the high/low clustering analysis. 


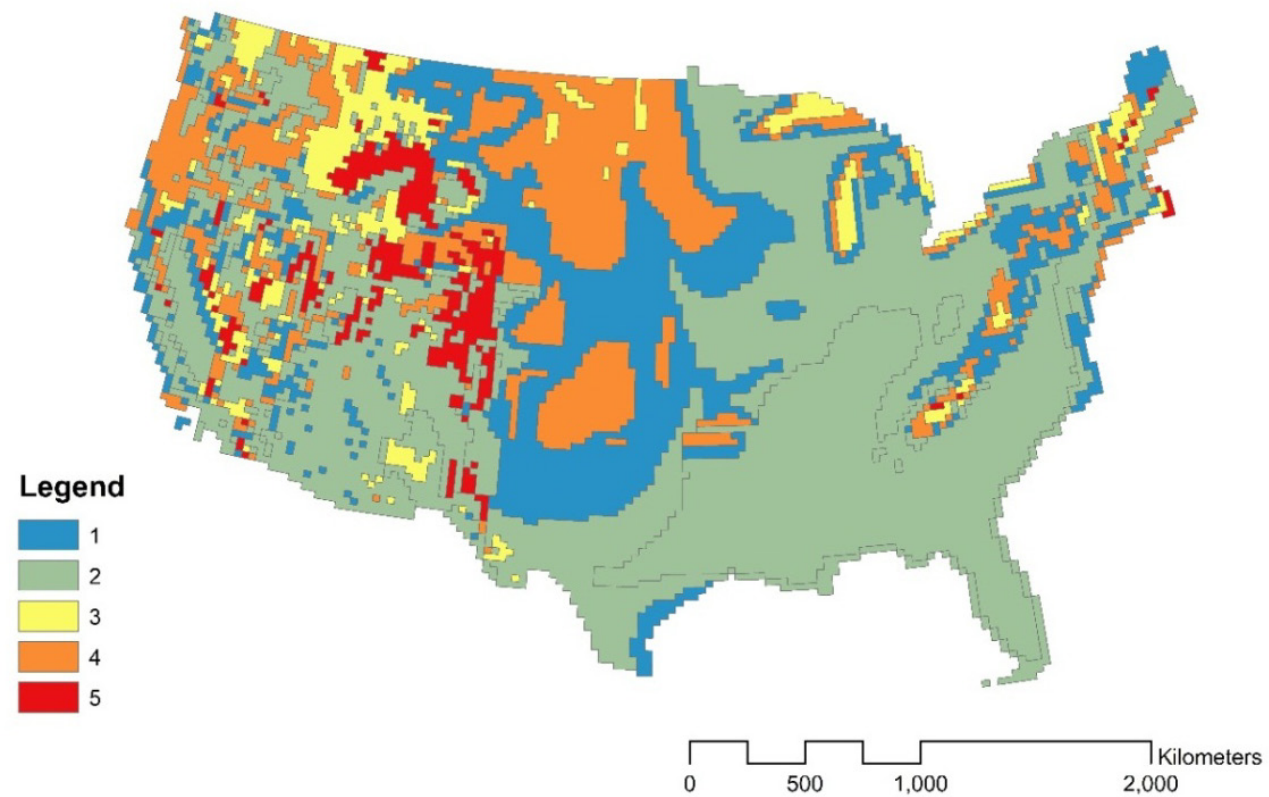

Figure 6. Five Groups of USA Wind Energy Power Classes from Grouping Analysis

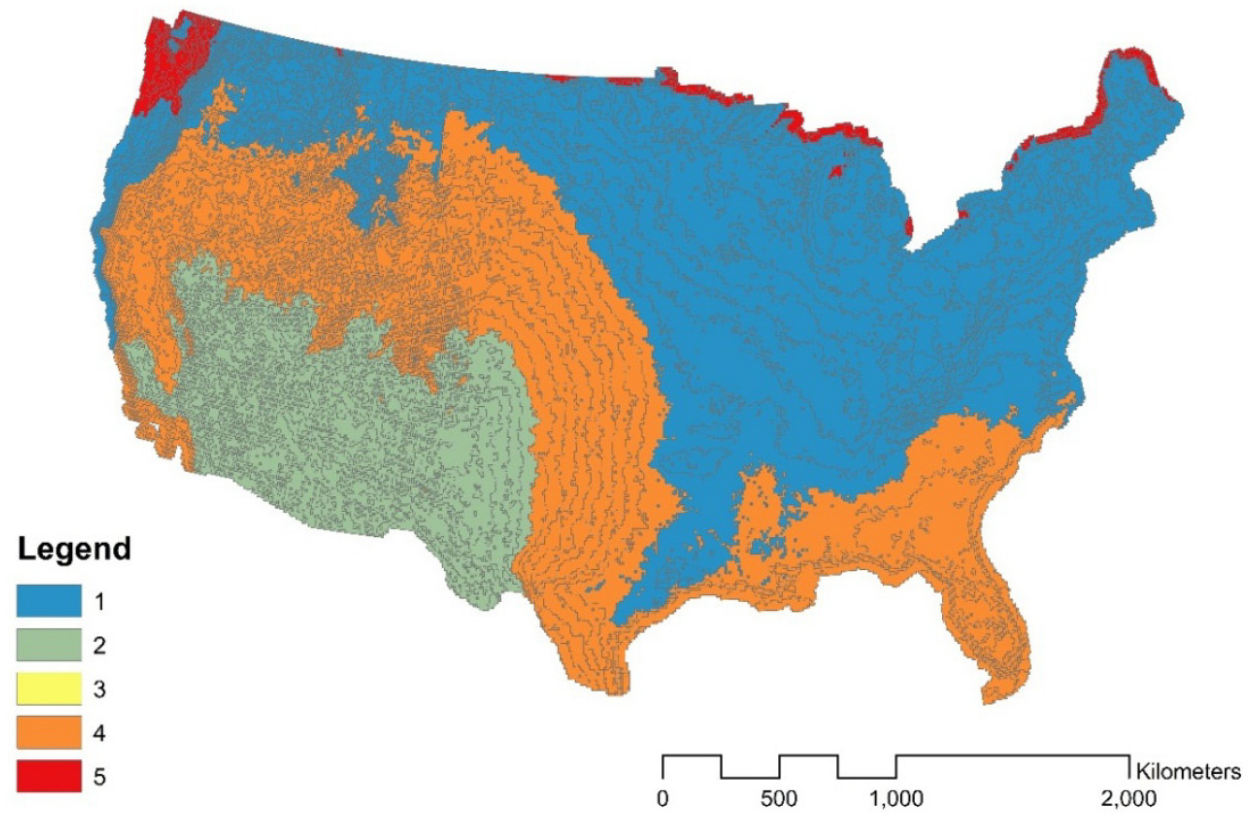

Figure 7. Five Groups of USA Annual Solar Energy Density from Grouping Analysis

The solar energy grouping analysis map (Figure 7) is highly similar to the original data (Figure 2) as well. There are three major groups on the grouping analysis result map from the north to the south of USA. The group distribution shapes are consistent with the original solar energy density data distribution. This is due to the fact that solar energy is regionally dependent based off of the Earth's geometry. There are some parts of the USA that will never get as much solar energy as other parts, which makes solar energy a predictable resource. All of the solar groups for the grouping analysis match the groups of the original solar depiction

\subsection{Hot-Spot Analysis Results}

The hot spot analysis result map of solar energy (Figure 8) shows that there is a large area of the highest concentration of high solar energy values (that is, hot spots) in the southwestern US and some along southern coasts. The areas that have a high concentration of low values, that is, cold spots, are disproportionate to the amount of area with a high concentration of high values. There is a greater amount of space of the hot spots than the cold spots. 


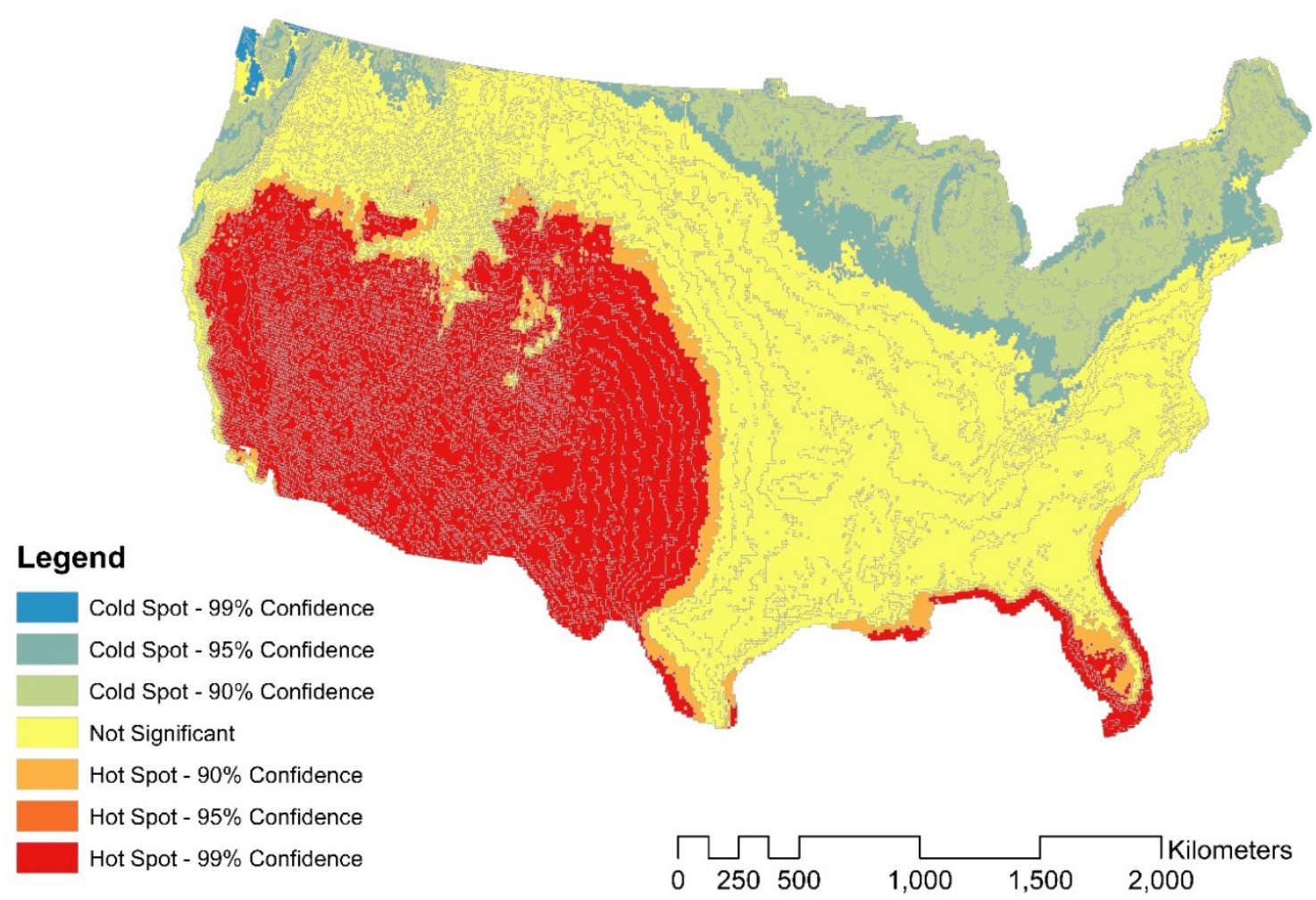

Figure 8. Hot/Cold Spots of USA Annual Solar Energy Density

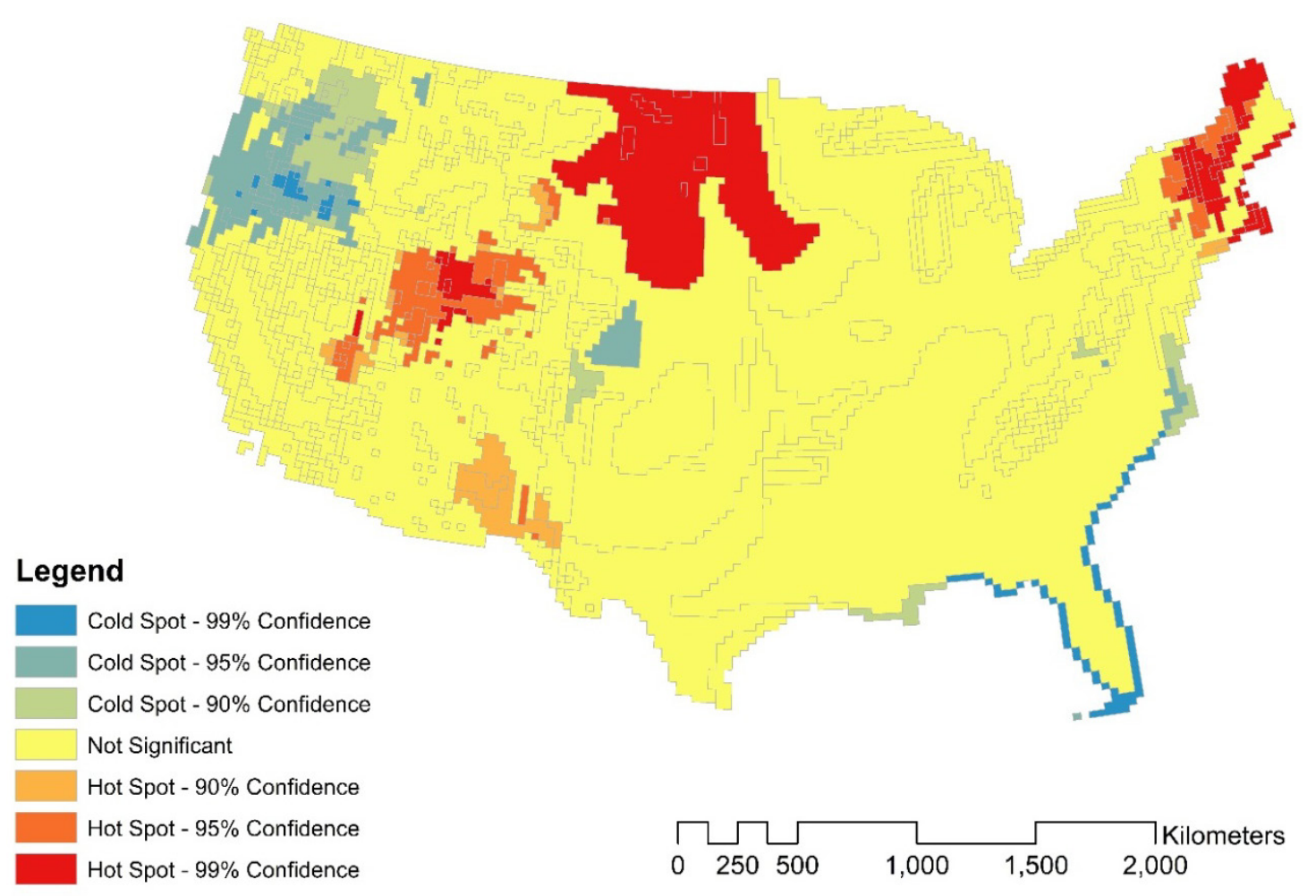

Figure 9. Hot/Cold Spots of USA Wind Energy Power Classes

The wind energy hot spot analysis result map (Figure 9) Wind is highly variable. Therefore, there is a greater area of shows a few hot spots and cold spots of wind energy in US. non-significant areas because the areas of high or low wind 
energy values are not particularly concentrated. This result is also consistent with the high/low clustering analysis.

\section{Conclusions, Discussion and Future Research}

This paper describes the spatial pattern analysis on the solar and wind renewable energy in USA. The study results help to give a more in depth understanding of the spatial patterns that the USA renewable energy resources have. The results show that the solar energy is more gradually spread out while the wind energy is variable and somewhat unpredictable without visualizations. There are large areas of land unsuitable for wind power and a few small areas that will have great yield of wind energy. The solar energy is spread out and could practically be used almost anywhere in USA with great yields. There is a tradeoff though due to the fact that the solar energy is variable day to day while the wind energy is steadier day to day since most wind power is harvested from such a great height.

The largest limitation in this study is that there were no practical geographic constraints that we can apply to the analysis. There could be a lot of area not included for a variety of reasons like roads, private property, or natural barriers. So possibly the areas that looked most promising for one resource or another could be completely off limits in terms of using that area for harvesting renewable energy. More constrains in land and diverse data sets could improve the quality of the research.

In the future, we may analyze different time periods of solar layers and examine the similarities and differences in their analysis results from the same analysis method. This can help to see how the solar energy distribution pattern changes in a year. We can also apply these analysis methods for other renewable energy resources like hydropower and geothermal. Like solar energy and wind power, hydropower and geothermal are geographically dependent. The energy potentials of geothermal (Hau, 2006) and hydropower energy potentials (Zaidi \& Khan, 2018) are already found, however, their spatial distributions are not explored though. We are also interested in comparing the energy distribution patters between USA and other territories, e. g. Europe, if GIS data is available to other territories. Another interesting research direction could be to explore areas where solar and wind coexist at a high concentration level. Existing research (Silva-Leon, Cioncolini, Nabawy, Revell, \& Kennaugh, 2019) shows it is possible to harvest both of them.

\section{REFERENCES}

[1] Anwarzai, M. A., \& Nagasaka, K. (2017). Utility-scale implementable potential of wind and solar energies for
Afghanistan using GIS multi-criteria decision analysis. Renewable and Sustainable Energy Reviews, 71, 150-160. doi:10.1016/j.rser.2016.12.048

[2] Augustine, C. (2012). Estimate of Geothermal Energy Resource in Major U.S. Sedimentary Basins (Presentation).

[3] Brewer, J., Ames, D. P., Solan, D., Lee, R., \& Carlisle, J. (2015). Using GIS analytics and social preference data to evaluate utility-scale solar power site suitability. Renewable Energy, 81, 825-836. doi:10.1016/j.renene.2015.04.017

[4] Chang, K.-t. (2015). Introduction to Geographic Information Systems (8 ed.): McGraw-Hill.

[5] Defne, Z. (2010). Multi-criteria assessment of wave and tidal power along the Atlantic coast of the southeastern USA.

[6] Elmore, R. (2017). Using GIS-based methods and lidar data to estimate rooftop solar technical potential in US cities. doi:10.1088/1748-9326/aa7225

[7] Fish, C. S., \& Calvert, K. (2016). Analysis of Interactive Solar Energy Web Maps for Urban Energy Sustainability. Cartographic Perspectives (85), 5-22.doi:10.14714/CP85.1 372

[8] Groppi, D., de Santoli, L., Cumo, F., \& Astiaso Garcia, D. (2018). A GIS-based model to assess buildings energy consumption and usable solar energy potential in urban areas. Sustainable Cities and Society, 40, 546-558. doi:10.1016/j.scs.2018.05.005

[9] Hasan, A., Sarwar, J., \& Shah, A. H. (2018). Concentrated photovoltaic: A review of thermal aspects, challenges and opportunities. Renewable \& Sustainable Energy Reviews, 94, 835-852. doi:10.1016/j.rser.2018.06.014

[10] Hau, E. (2006). Wind Turbines: Fundamentals, Technologies, Application, Economics (Vol. 2nd ed). Berlin: Springer.

[11] Hemery, L. G., Henkel, S. K., \& Cochrane, G. R. (2017). Oregon OCS seafloor mapping; selected lease blocks relevant to renewable energy. Open-File Report - U.S. Geological Survey. doi:10.3133/ofr20171045

[12] Jangid, J., Bera, A. K., Joseph, M., Singh, V., Singh, T. P., Pradhan, B. K., \& Das, S. (2016). Potential zones identification for harvesting wind energy resources in desert region of India - A multi criteria evaluation approach using remote sensing and GIS. Renewable and Sustainable Energy Reviews, 65, 1-10. doi:10.1016/j.rser.2016.06.078

[13] Lopez, A., Roberts, B., Heimiller, D., Blair, N., \& Porro, G. (2012). U.S. Renewable Energy Technical Potentials: A GIS-Based Analysis. Renewable Energy, 40.

[14] Mahdy, M., \& Bahaj, A. S. (2018). Multi criteria decision analysis for offshore wind energy potential in Egypt. Renewable Energy, 118, 278-289. doi:10.1016/j.renene.201 7.11 .021

[15] Milici, R. C., Flores, R. M., \& Stricker, G. D. (2013). Coal resources, reserves and peak coal production in the United States. International Journal of Coal Geology, 113, 109-115. doi:10.1016/j.coal.2012.10.002

[16] Mohtasham, J. (2015). Review Article-Renewable Energies. Energy Procedia, 74 (Supplement C), 1289-1297. doi:10.1016/j.egypro.2015.07.774 
[17] Niblick, B., \& Landis, A. E. (2016). Assessing renewable energy potential on United States marginal and contaminated sites. Renewable and Sustainable Energy Reviews, 60, 489-497. doi:10.1016/j.rser.2015.12.045

[18] Schelly, C., \& Price, J. (2014). Utilizing GIS to Examine the Relationship between State Renewable Portfolio Standards and the Adoption of Renewable Energy Technologies. ISPRS International Journal of Geo-Information, 3(1), 1.

[19] Squalli, J. (2017). Renewable energy, coal as a baseload power source, and greenhouse gas emissions: Evidence from U.S. state-level data. Energy, 127, 479-488. doi:10.1016/j.energy.2017.03.156

[20] Xu, J., Song, X., Wu, Y., \& Zeng, Z. (2015). GIS-modelling based coal-fired power plant site identification and selection. Applied Energy, 159, 520-539.doi:10.1016/j.apenergy.2015 .09 .008

[21] Zhang, J., Cho, H., Luck, R., \& Mago, P. J. (2018). Integrated photovoltaic and battery energy storage (PV-BES) systems: An analysis of existing financial incentive policies in the US. Applied Energy, 212, 895-908. doi:10.1016/j.apenergy.2017.12.091. 